Article

\title{
Assessing the Extinction Risk of Heterocypris incongruens (Crustacea: Ostracoda) in Climate Change with Sensitivity and Uncertainty Analysis
}

\author{
Nicolò Bellin (D), Rachele Spezzano and Valeria Rossi *(D) \\ Department of Chemistry, Life Sciences and Environmental Sustainability, University of Parma, \\ Viale delle Scienze 11/A, I-43124 Parma, Italy; nicolo.bellin@unipr.it (N.B.); \\ rachele.spezzano@studenti.unipr.it (R.S.) \\ * Correspondence: valeria.rossi@unipr.it; Tel.: +39-0521-905612
}

Citation: Bellin, N.; Spezzano, R.; Rossi, V. Assessing the Extinction Risk of Heterocypris incongruens (Crustacea: Ostracoda) in Climate Change with Sensitivity and Uncertainty Analysis. Water 2021, 13, 1828. https:// doi.org/10.3390/w13131828

Academic Editor: Hodon Ryu

Received: 6 May 2021

Accepted: 28 June 2021

Published: 30 June 2021

Publisher's Note: MDPI stays neutral with regard to jurisdictional claims in published maps and institutional affiliations.

Copyright: (c) 2021 by the authors. Licensee MDPI, Basel, Switzerland. This article is an open access article distributed under the terms and conditions of the Creative Commons Attribution (CC BY) license (https:// creativecommons.org/licenses/by/ $4.0 /)$.
Abstract: Organisms respond to climate change in many different ways and their local extinction risk may vary widely among taxa. Crustaceans from freshwater temporary ponds produce resting eggs to cope with environmental uncertainty and, as a consequence, egg banks have a fundamental role for population persistence. The egg bank dynamics of six clonal lineages of Heterocypris incongruens (Ostracoda) from Northern Italy were simulated. Clonal lineages W1 and W2 are the most common "winter ecotypes", clonal lineages S1 and S2 are allochthonous "summer ecotypes" and clonal lineages I1 and I2 are relatively rare and generalist in terms of seasonality. Fecundity and proportion of resting eggs vary by clonal lineage, temperature and photoperiod. The clonal extinction risk was estimated in present climate conditions and under climate change. For comparison, and to assess the potential colonization of northern ponds, clonal lineages from Lampedusa Island (Southern Italy), $\mathrm{L}$, were considered. Cohen's general model was used for simulating egg bank dynamics and the extinction rate of each clonal lineage was estimated with uncertainty analysis. A 30 year simulation in present and climate change conditions was carried out. Extinction rates were lower in climate change conditions than in present conditions. Hydroperiod, hatching rate and egg deterioration rate were the critical factors that affected extinction rates. Extinction rates varied among clonal lineages. This suggests that $H$. incongruens might be able to have multiple responses to climate change due to its genetic diversity. In climate change conditions, W clonal lineages underwent a niche expansion, while a mismatch between photoperiod and hydroperiod might generate a detrimental effect on the phenology of summer S clonal lineages that might cause their extinction. Southern clonal lineages L, showing an intermediate extinction rate, might colonize northern temporary ponds.

Keywords: hydroperiod; RCP 8.5 scenario; egg bank; Cohen's model; ephemeral ponds; clonal diversity

\section{Introduction}

Climate change may be an important threat to global biodiversity, but the extent of species loss will depend on the details of how species respond to changing climates and predicting how species will respond may be very difficult. Modelling studies have shown that extinction risks may vary widely depending on specific assumptions, model type, study regions and taxon [1-3]. For example, species may respond to changing environments in several ways: dispersing to track the original climate conditions over space, shifting their niche via genetic adaptation, through phenotypic plasticity of fitness-related traits, or going extinct [4-11]. Although a number of studies have analyzed species response to climate change, few studies have explored it from an intraspecific perspective [12-14].

Organisms, such as crustaceans, that live in ephemeral freshwater habitats have evolved dormant stages in response to environmental variability that can lead to unsuitable conditions [15-18]. In analogy to plant seed banks, resting eggs remain dormant in the dry sediment and may accumulate to form a so-called egg bank [19-21]. In 1966, Cohen [22] 
proposed a general model of selection on dormancy and germination in unpredictable environments. The highly quoted model has been applied to describe the optimal hatching strategy of resting eggs of crustaceans and rotifers in ephemeral ponds [23-26]. The partial hatching from the egg bank during each new inundation is part of a bet-hedging strategy that buffers environmental fluctuations, preventing demographic catastrophes when the hatchlings are unable to complete their life cycle and produce new resting eggs [27-30]. Environmental cues, such as temperature and photoperiod, as well as maternal effects, may act as signals of a suitable environment that allow synchronizing hydroperiod and life cycle, and reduce extinction risk. On the other hand, prolonged drought, predation and diseases can reduce the number of eggs and might lead to local extinction [31-33]. An increase in temperature may reduce the developmental time of ectotherms but, due to evaporation, it may also shorten the hydroperiod and impose time constraints on reproduction [34-36]. Pinceel et al. [37] calculated that extinction risks of the fairy shrimp Branchipodopsis wolfi (Crustacea Branchiopoda, Anostraca) from rock pools in South Africa increase drastically once the median hydroperiod drops below a critical threshold of 12 days.

According to the projections of climate change for the Euro-Mediterranean region, Italy should be subjected to substantial warming in all seasons, with a maximum during summer and a minimum in winter (Euro-Mediterranean Centre for Climate Change (CMCC), 2010). In addition, a significant increase in the variability among years and the occurrence of extreme events, such as heatwaves, drought and heavy precipitations, are expected. Precipitations are expected to severely decrease in summer and, to a lesser extent, in spring and autumn. In winter, precipitations should increase in Northern Italy and should decrease in the South.

Ostracods, the most diverse class of Crustacea, are important components of temporary ponds and survive dry periods as dormant eggs resistant to desiccation [38]. Heterocypris incongruens is a very common species found worldwide and is the most widespread species in temporary ponds and ricefields in Northern Italy [39]. In all female parthenogenetic populations, different clonal lineages have been recorded and seasonal succession of different ecotypes has been described [40-42]. Fecundity and proportion of resting eggs vary depending on clonal lineage, environmental conditions (e.g., temperature and photoperiod) and their interactions $[33,40,41,43]$. During the whole reproductive cycle, parthenogenetic females of $H$. incongruens can produce resting and non-resting, smaller eggs, both genetically homogeneous [44]. Most resting eggs usually hatch synchronously at the start of each hydroperiod, but changes in the physico-chemical environmental conditions and maternal effects may affect the hatching phenology, including the spread of the hatching time of cohorts of resting eggs over more than one hydroperiod [45].

In a previous paper, we used the general model proposed by Cohen [22] to simulate egg bank dynamics of $H$. incongruens in vernal temporary ponds on Lampedusa Island (Southern Italy) [46]. Here, the simulated egg bank dynamics of six different clonal lineages of $H$. incongruens from Northern Italy, in present climate conditions and in future climate change conditions, are reported. It was hypothesized that the extinction risk of $H$. incongruens may vary among different clonal lineages and that this species might be able to respond to climate change due to its genetic diversity. Moreover, the potential migration and colonization of northern ponds by clonal lineages from the south in climate change conditions was assessed $[33,46]$. Uncertainty, regionalized sensitivity (RSA) and global sensitivity analysis (GSA) were carried out to evaluate the model in terms of output uncertainty, interaction terms and importance of factors for the model output [47-50].

\section{Materials and Methods}

The Po plain is located in Northern Italy. It extends approximately in an east-west direction, with an area of $46,000 \mathrm{~km}^{2}$. This basin is mainly made up of alluvial, deltaic and marine deposits, where the most common lithological types are sedimentary and composed of sand, clay deposits and clay sands and different coarse debris [51]. 


\subsection{Potential Hydroperiod and Hydroperiod Unpredictability}

To estimate the potential hydroperiod in temporary ponds in this area, the monthly water balance was calculated as the difference between rainfall and potential evapotranspiration and the effective infiltration in the soil. Potential evapotranspiration is the amount of water that could evaporate and was calculated using the algorithm proposed by Thornthwaite (1948) (http: / / onlinecalc.sdsu.edu / accessed on 3 March 2020). This approach was useful in producing hydroperiod estimates on Lampedusa [46]. The effective infiltration in the soil was estimated by the product of the presumed infiltration (Ip), i.e., the difference between rainfall and potential evapotranspiration, and the effective infiltration coefficient (EIC). An effective infiltration coefficient varies in different lithological sites depending on several factors such as slope gradient, plant coverage and rock porosity [52,53]. Based on several lithological studies conducted in the Po plain, we estimated an average EIC value of 0.55 [52].

To estimate the potential hydroperiod in present conditions, we considered 30 years of rainfall data and mean temperatures (from 1990 to 2019) from a weather station located in the center of the Po plain (Arpae Emilia-Romagna) (Parma: $44^{\circ} 48^{\prime} \mathrm{N}, 10^{\circ} 19^{\prime} \mathrm{E}$ ). We considered 30 years because the climate usually is defined as the average weather for a particular region and period of time, taken over 30 years. For estimating the potential hydroperiod in climate change conditions, we used the platform of KNMI Climate Explorer [54] (http:/ / climexp.knmi.nl; accessed: 3 March 2020) for long forecasting. As future projection, it was considered a period of time of 30 years from 2020 to 2050. In order to obtain the average monthly values of temperatures and precipitations, an ensemble model from CMIP 5 from the IPCC AR5 report [55] was used and a square grid located in Northern Italy was selected $\left(42^{\circ} 30^{\prime} \mathrm{N}-45^{\circ} 00^{\prime} \mathrm{N}, 10^{\circ} 00^{\prime} \mathrm{E}-12^{\circ} 30^{\prime} \mathrm{E}\right)$. The climate variables were recorded under the representative concentration (RCP) 8.5 scenario [55] that corresponds to the pathway with the highest greenhouse gas emissions. For present and climate change conditions, the monthly water balance values were converted to probabilities using a binary system. To each month, a binary value representing the absence or presence of water in a given ephemeral pond was assigned: 0 if the water balance was negative (supposing the pond was dry) and 1 if the water balance was positive (supposing the pond was wet). The monthly probability that the water balance in a given pond is positive (P in Equation (2)) was calculated by computing the sum of the water presence, month by month, divided by the total observations (30 years).

To assess the hydroperiod unpredictability, the coefficient of variation of water balance [33] and the Shannon entropy equation were used, considering as variable the binary value absence/presence of water in the ephemeral pond. The entropy of a Bernoulli variable measures the quantity of uncertainty associated with a particular output and it was expressed as:

$$
\text { Unpredictability }=-\mathrm{P} \times \log 2(\mathrm{P})-(1-\mathrm{P}) \times \log 2(1-\mathrm{P})
$$

where $\mathrm{P}$ is the probability that the water balance is positive. When the probability that the water balance is positive, i.e., is equal to 0.5 , the system showed the highest unpredictability, meanwhile when it approximates values of 0 or 1 , the system showed the lowest unpredictability.

\subsection{Clonal Lineages}

To assess the production of resting eggs per female (see below Equation (2)), data on the fecundity of genetically different clonal lineages of $H$. incongruens were obtained by life table experiments [41]. Six parthenogenetic clonal lineages of H. incongruens from Po valley were considered. Two W-type clonal lineages (W1 and W2) are the most common and widespread, both in ricefields and temporary ponds [41]. They are typical "winter ecotypes", autochthonous and well adapted to the local continental seasonal conditions. Two S-type clonal lineages (S1 and S2) are considered allochthonous, and it was hypothesized that they might have been introduced from Asia [56]. They are "summer ecotypes", well 
adapted to warmer conditions and found in ricefields in late spring and summer only. Two I-type clonal lineages (I1 and I2) can be considered generalists in terms of seasonality. They are relatively rare with very high variability in their abundance among years in nature while they reached the highest densities in laboratory conditions. Temperature and photoperiod are the most relevant factors driving seasonality, survivorship, fecundity, resting eggs percentage and hatching phenology in W and S-type clonal lineages. The production of resting eggs seems to be unaffected by temperature and photoperiod in I-type clonal lineages. For comparison, and to assess the potential colonization of northern ponds, data on the fecundity of clonal lineages L from Lampedusa Island (South Italy) were considered [33,46]. They are "winter ecotypes" and their fecundity depends on temperature and photoperiod. In life table experiments, clonal lineages were replicated across experiments that were carried out at $24^{\circ} \mathrm{C}$ and 12 light hours $/ 12$ dark hours photoperiod, corresponding to spring and fall seasons (April-June), at $12{ }^{\circ} \mathrm{C}$ and 8 light hours $/ 16$ dark hours photoperiod, corresponding to the winter season, and at $28{ }^{\circ} \mathrm{C}$ and 16 light hours / 8 dark hours photoperiod, corresponding to the summer season $[33,41]$ (Table S1 in Supplementary Materials). We assumed that the risk related to the reproduction (production of a new cohort of resting eggs) in ephemeral habitats varies according to the potential hydroperiod and that only one generation may complete a reproductive cycle in a single hydroperiod [46].

\subsection{Cohen's Model, Egg Bank Dynamics and Extinction Rate}

To simulate egg bank dynamics, Cohen's model [22] was used to compute the growth rate of seed banks in unpredictable environments. Cohen's model for seed banks considers the production of new seeds per individual as a gain term, while the deterioration and the germination rates act as losses. Cohen's model also introduces a factor relating to the probability of observing a suitable environment to start the life cycle. The number of eggs produced by a female in 1 life cycle, and each growth and each reproductive cycle is considered to be completed within a discrete-time interval. The average number of hatching eggs is a variable depending on the number of resting eggs produced by the previous generation and on environmental conditions. It was assumed to be independent of the population density. We computed the annual growth rate of the egg bank with Cohen's equation [22]:

$$
\ln (\lambda)=(1-\mathrm{P}) \times \ln [(1-\mathrm{H}) \times(1-\mathrm{D})]+\mathrm{P} \times \ln [(1-\mathrm{H}) \times(1-\mathrm{D})+\mathrm{H} \times \mathrm{Y}]
$$

$\mathrm{H}$ is the hatching rate, $\mathrm{P}$ is the probability that the water balance is positive, $\mathrm{Y}$ is the mean number of resting eggs produced per female and $\mathrm{D}$ is the deterioration rate. The egg bank dynamics $\left(E b_{t}\right)$ were simulated assuming the exponential growth over 30 time steps (years):

$$
\mathrm{Eb}_{\mathrm{t}}=\mathrm{Eb}_{0} \times \mathrm{e}^{(\ln (\lambda) \times \mathrm{t})}
$$

$\mathrm{Eb}_{\mathrm{t}}$ is the number of resting eggs in the egg bank at time $t, \mathrm{~Eb}_{0}$ is the number of resting eggs at time 0 and $\ln (\lambda)$ is the annual egg bank growth rate computed by Cohen's equation (Equation (2)). It was assumed that there are no effects of competition and predation on the egg bank dynamics. An interval of 30 years of simulation in a specific climate regime between 2020 and 2050 was considered. Climate regime describes the average conditions and the variability of temperature and precipitation in a given region over a period of 30 years. At the last time step, 30 years, the condition of the population egg bank was recorded by binary output. The binary output of the egg bank simulation was expressed as:

$$
\text { Extinction }=\mathrm{Eb} 30<1 \text { or Viability }=\mathrm{Eb} 30 \geq 1
$$

Extinction rate per clonal lineage and climate condition were computed as a proportion of extinction events. 


\subsection{Factor Fixing: Morris' Method}

A factor fixing analysis was performed in order to evaluate which factor among hatching rate $(\mathrm{H})$, the probability that the water balance is positive $(\mathrm{P})$, deterioration rate (D), mean number of resting eggs produced per female $(\mathrm{Y})$ and number of resting eggs at time $0\left(\mathrm{~Eb}_{0}\right)$, was the least important in determining the extinction or the viability of the egg bank [47]. The least important factor with the lowest interaction level could be fixed at any constant value without loss of information in the model output. Preliminarily, we performed the Morris method, an OAT procedure (one step at a time) [47]. Each factor was sampled 1 time in its own range and the other was kept constant to compute the model output. The ranges of hatching rate $(\mathrm{H})$, probability that the water balance is positive $(\mathrm{P})$ and deterioration rate $(\mathrm{D})$ were set between 0 and 1 . The mean number of resting eggs produced per female $(\mathrm{Y})$ was sampled between a minimum value of 0 and a maximum value of 187 [43]. The range of the number of resting eggs at time $0\left(\mathrm{~Eb}_{0}\right)$ was set between 10 and 1000. This procedure was repeated $r$ times (where $r=100$ ), which leads to $r(k+1)=600$ runs, where $k=5$ was the number of input factors $\left(H, P, Y, D\right.$, and $\left.E_{0}\right)$. From the application of the Morris method it was estimated: the mean absolute value for elementary effect $\left(\mu j^{*}\right)$ for $j$-factor, a measure of the importance on dispersion in the model output, and the standard deviation of the elementary effects $(\sigma j)$, a measure of the degree of the interaction effects for the j-factor with other factors. Low values of $\mu j^{*}$ indicated that one factor was not important in the variation of the model output. High values of oj revealed how strong the interaction with other factors might be. The analysis was performed with $R$ package sensitivity [57]. This analysis revealed that the most important factors with high interaction levels were the probability that the water balance is positive $(\mathrm{P})$, deterioration rate (D) and hatching rate (H) (Figure S1 in Supplementary Materials). The number of resting eggs at time $0\left(\mathrm{~Eb}_{\mathrm{o}}\right)$ was the least important factor, with the lowest interaction level. For this reason, in the following analysis, it was set as a fixed factor with a value equal to 10 .

\subsection{Uncertainty Analysis, Regionalized Sensitivity Analysis (RSA) and Global Sensitivity Analysis (GSA)}

In order to perform the sensitivity and uncertainty analysis of the exponential growth model (Equation (3)), we assigned and estimated the prior distribution for 4 factors: hatching rate $(\mathrm{H})$, the probability that the water balance is positive $(\mathrm{P})$, mean number of resting eggs produced per female $(\mathrm{Y})$ and deterioration rate $(\mathrm{D})$ for each clone, in present and climate change conditions [47]. The probability that the water balance is positive $(\mathrm{P})$ and mean number of resting eggs produced per female $(\mathrm{Y})$ distributions were fitted from data with the maximum likelihood method. For the hatching rate $(\mathrm{H})$ and the deterioration rate (D), uniform distributions were assumed (Table S2). The analysis was carried out with the $R$ package fitdistrplus [57]. Uncertainty analysis was performed to estimate the probability of extinction and viability of the egg bank over 30 years for each clone, in present and climate change conditions [48]. To obtain the probability of extinction and viability of the egg bank, Latin Hypercube Sampling (LHS) [58] was performed 1000 times, assuming the estimated prior distribution for each factor (Table S2). The results made it possible to quantify the extinction rate of each clone under 2 climate conditions (R script S1 in Supplementary Materials).

Regionalized sensitivity analysis (RSA) was performed to evaluate the rank of each factor $(\mathrm{H}, \mathrm{P}, \mathrm{Y}$ and $\mathrm{D})$ in determining the extinction or viability of the egg bank. For each factor, we obtained 2 cumulative density functions ( 1 for extinction and 1 for viability). The Kolmogorov-Smirnov test was used to evaluate the difference between the 2 functions [59]. Each factor $(\mathrm{H}, \mathrm{P}, \mathrm{Y}$ and $\mathrm{D})$ was grouped into 3 sensitivity classes, based on the significance level of Kolmogorov-Smirnov test: critical $(\alpha<0.01)$, important $(0.01 \leq \alpha \leq 0.10)$ and insignificant $(\alpha>0.10)$. Considering only the extinction output, the interaction between pairs of factors by correlation coefficients $(\rho)$ was evaluated. To examine higher-order interaction terms among factors and to improve the ranking criteria, a global sensitivity 
analysis (GSA) was applied according to Sobol's method [47,49,60]. For each factor and clone in present and climate change conditions, we estimated the first index ( $\mathrm{Si}$ ) (main effect of each factor) and total index (STi) (main effect of each factor plus interaction with the other factors). A bootstrapped procedure was used to obtain 1000 replicates of each index to estimate the standard error. The analyses were performed with $\mathrm{R}$ package sensitivity and pse [57].

\section{Results}

According to potential hydroperiod estimations, in present conditions, the probability that the water balance is positive (P) was higher in winter and fall and declined from spring to summer, reaching a value of 0 from June to September (Figure 1). Under climate change conditions, the probability that the water balance is positive $(\mathrm{P})$ was higher than under present conditions from November to March. The dry season started earlier (April) and lasted longer than in present conditions (in October, the probability that the water balance is positive $(\mathrm{P})$ was lower than in present conditions). Under present conditions, environmental unpredictability was high from October to May, reaching the maximum values in February, March and October. In simulation under climate change conditions, in all months, we found an overall reduction of the hydroperiod unpredictability (measured as coefficient of variation of water balance or as entropy). This reduction was due to a shortening of the wet season and a lengthening of the dry one.

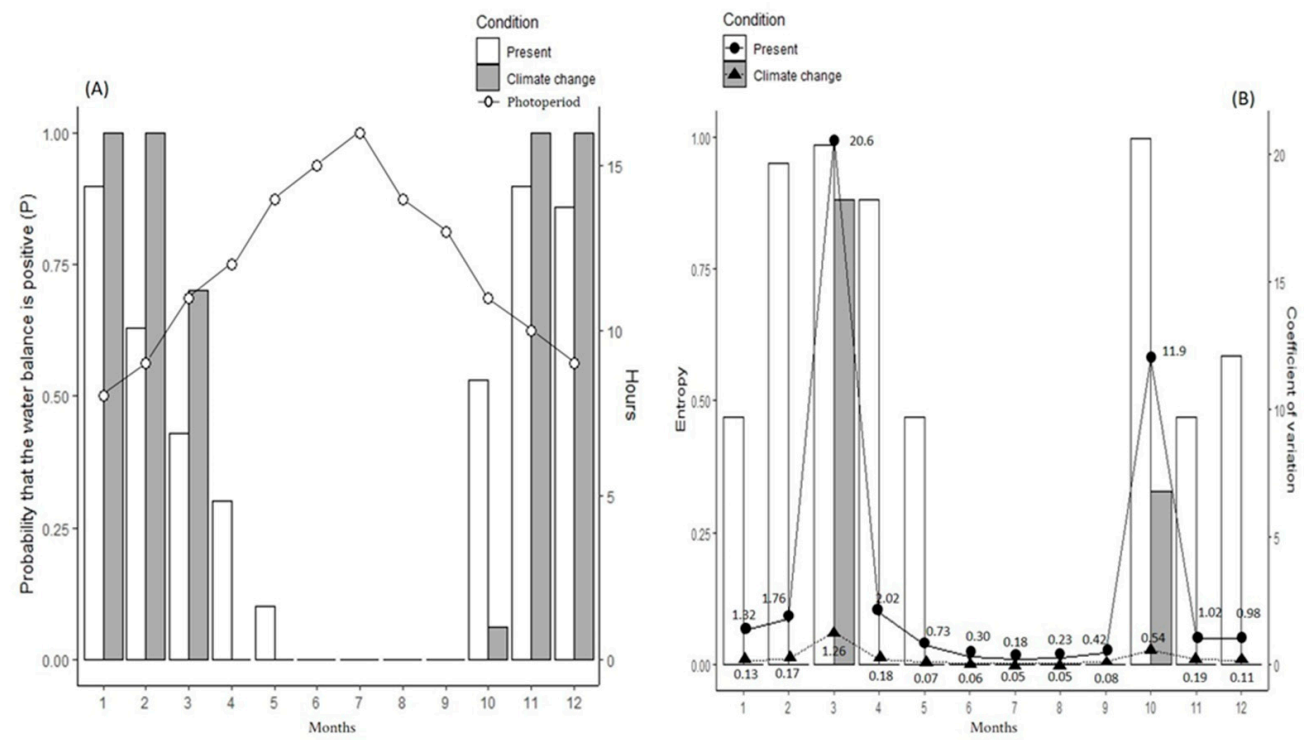

Figure 1. Panel (A) shows the histograms of the annual probability that the water balance is positive (P) under 2 different climatic conditions: present (white) and climate change (grey). The photoperiod of the Po plain was reported as lines and circles. Panel (B) shows the measures of environmental uncertainty: left $y$-axis is referred to the histograms of the entropy in present condition (white) and climate change (grey). The right $y$-axis is relative to coefficient of variation (CV) in 2 climatic conditions: present (continuous line and circle) and climate change (dashed line and triangle).

For all clones, the extinction rate was lower under climate change than under present conditions (Figure 2). Among the northern clones, the winter W1 and W2 showed the lowest extinction rate in both conditions. W1 and W2 clones showed a reduction of the extinction rate respectively equal to $5 \%$ and $3 \%$ under climate change. The clones from Lampedusa, $\mathrm{L}$, showed an intermediate extinction rate, with a reduction of $6 \%$ in climate change conditions. Clones I1 and I2 showed the highest extinction rates in both conditions, with a reduction of $4 \%$ and $9 \%$ in climate change conditions. 


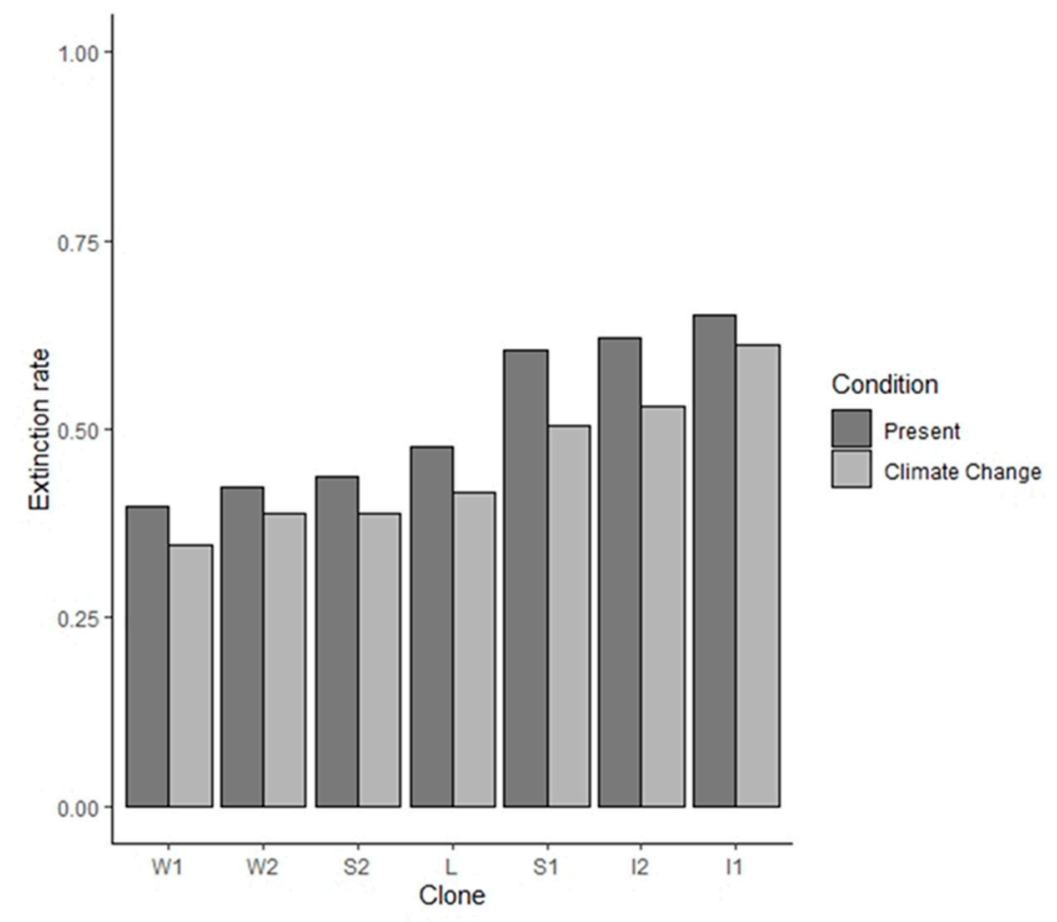

Figure 2. Extinction rates obtained by uncertainty analysis for each clone in present (dark grey) and climate change (light grey) conditions.

In general, the most important factors varied according to conditions and clones. Under present conditions, the deterioration rate (D) was critical $(\alpha<0.01)$ for all clones, except for W2 and S2, for which it was important and insignificant, respectively. The probability that the water balance is positive $(\mathrm{P})$ was critical $(\alpha<0.01)$ for all clones, except for the northern clone I2 (for which it was important) and insignificant for the southern clones $\mathrm{L}$ (Figure 3). Under both conditions, the hatching rate $(\mathrm{H})$ ranked as a critical factor for all clones $(\alpha<0.01)$, while the mean number of resting eggs produced per female $(\mathrm{Y})$ was critical $(\alpha<0.01)$ for the northern clones S1, S2 and I2 and the southern clones L.

Considering only the extinction event, for all clones, under both present and climate change conditions, the hatching rate $(\mathrm{H})$ and the deterioration rate $(\mathrm{D})$ were negatively correlated while the probability of positive water balance $(\mathrm{P})$ and deterioration rate $(\mathrm{D})$ were positively correlated (Figure 4 and Table S3). The mean number of resting eggs produced per female $(\mathrm{Y})$ and the egg deterioration rate $(\mathrm{D})$ were positively correlated only for clone I1. In present conditions, the values of hatching rate $(\mathrm{H})$ and the probability that the water balance is positive $(\mathrm{P})$ were positively correlated for all clones but $\mathrm{S} 1$ and $\mathrm{L}$. The hatching rate $(\mathrm{H})$ and the mean number of resting eggs produced per female $(\mathrm{Y})$ were positively correlated only for clone I1. The probability of positive water balance $(\mathrm{P})$ and the mean number of resting eggs produced per female $(\mathrm{Y})$ were negatively correlated for clones $\mathrm{I} 2$ and S1. In climate change conditions, the hatching rate $(\mathrm{H})$ and the probability that the water balance is positive (P) were positively correlated for clones W1, S2 and I1. They were negatively correlated for the southern clones L. The probability that the water balance is positive $(\mathrm{P})$ and the mean number of resting eggs produced per female $(\mathrm{Y})$ were negatively correlated for the northern clones I2, S1 and I1 and the southern clones L. 
(A)

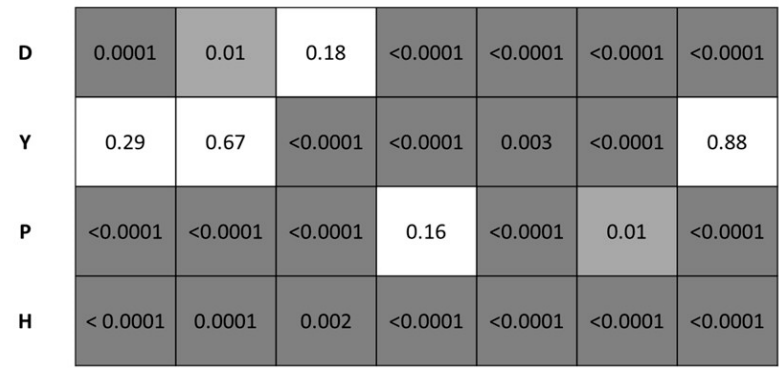

$\begin{array}{lllllll}\text { W1 } & \text { W2 } & \text { S2 } & \text { L } & \text { S1 } & 12 & 11\end{array}$

RANKING

(B)
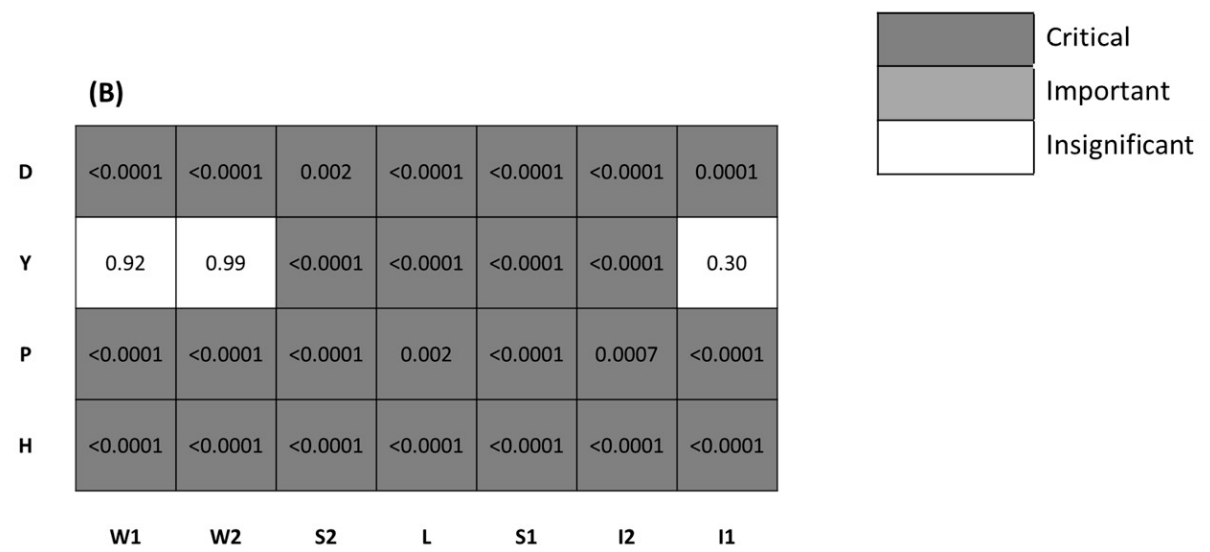

Figure 3. Heatmaps from the Kolmogorov-Smirnov tests for each factor relative to each clone in two conditions: present (panel A) and climate change (panel B). The $p$-values $(\alpha)$ from the regionalized sensitivity analysis are reported and the ranking criteria labelled with different colors (critical: dark grey; important: light grey; and insignificant: white).

\begin{tabular}{|c|c|c|c|c|c|c|c|}
\hline W1 & $\oplus \oplus$ & ns ns & $\odot \odot$ & ns ns & $\oplus \oplus$ & ns ns & \\
\hline W2 & $(\mathrm{ns}$ & ns ns & $\odot \odot$ & ns ns & $\oplus \oplus$ & ns ns & \multirow{7}{*}{$\begin{array}{l}\bigcirc \text { Present } \\
\text { Climate change } \\
\text { + Positively correlated } \\
\text { - Negatively correlated } \\
\text { ns Not significant }\end{array}$} \\
\hline S2 & $\oplus \oplus$ & ns ns & $\odot \odot$ & ns ns & $\oplus \oplus$ & ns ns & \\
\hline $\mathrm{L}$ & $n s \odot$ & ns ns & $\odot \odot$ & ns $\odot$ & $\oplus \oplus$ & ns ns & \\
\hline S1 & ns ns & ns ns & $\odot \odot$ & $\odot \odot$ & $\oplus \oplus$ & ns ns & \\
\hline 12 & ๑ns & ns ns & $\Theta \odot$ & $\odot \odot$ & $\oplus \oplus$ & ns ns & \\
\hline I1 & $\oplus \oplus$ & $\bigoplus \mathrm{ns}$ & $\odot \odot$ & ns $\odot$ & $\oplus \oplus$ & $\oplus \oplus$ & \\
\hline & $\mathrm{H}-\mathrm{P}$ & $\mathrm{H}-\mathrm{Y}$ & $H-D$ & $P-Y$ & $P-D$ & $Y-D$ & \\
\hline
\end{tabular}

Figure 4. Pairwise correlation coefficients $(\rho)$ computed between factors (the hatching rate $(\mathrm{H})$, probability that the water balance is positive $(\mathrm{P})$, mean number of resting eggs produced per female (Y) and deterioration rate (D) for each clone (W1, W2, S2, L, S1, I2, I1) in present and climate change conditions (Table S3).

Sobol's method confirmed that the main effect of each factor (first index Si) and the main effect of each factor plus interaction with the other factors (total index STi) in determining extinction, varied according to conditions and clones. Under present conditions, the deterioration rate (D) showed the highest first index (SD) for clones S1 and I1. 
In climate change conditions, a general increase of $\mathrm{SD}$, compared with present conditions, was observed for all clones but W1 and S1 (Figure 5 and Figure S2 in Supplementary Materials). Under present conditions, the mean number of resting eggs produced per female $(\mathrm{Y})$ showed the lowest value of the first index and total index for all clones.
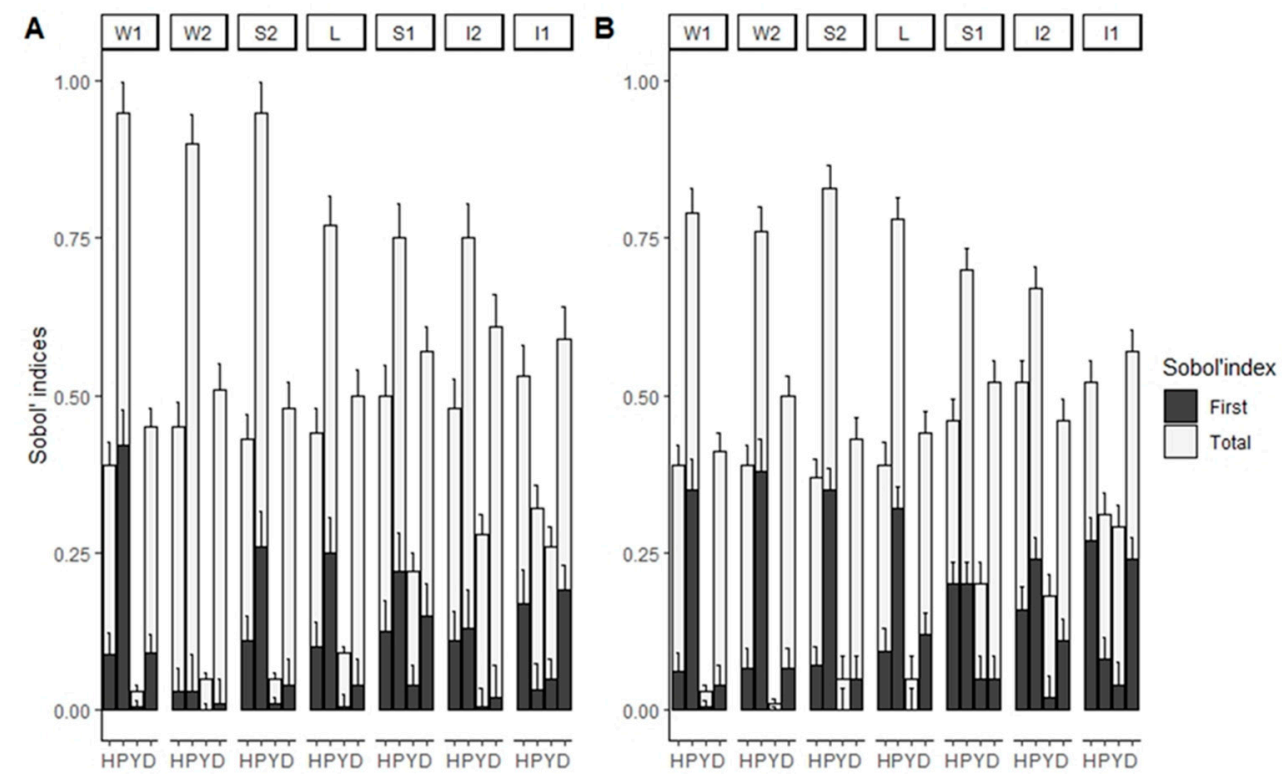

Figure 5. Sobol's indices: first index (dark grey) and total index (light grey) for each factor (the hatching rate $(\mathrm{H})$, probability that the water balance is positive $(\mathrm{P})$, mean number of resting eggs produced per female (Y) and deterioration rate (D) and each clone (W1, W2, S2, L, I2, S1, I1) in 2 climatic conditions: present (panel A) and climate change (panel B). The error bar represent the standard error estimated from the bootstrap procedure $(n=1000)$.

Under climate change conditions, the first index of the probability that the water balance is positive, SP increased when compared to present conditions for all clones (Figure 5 and Figure S2 in Supplementary Materials) except W1 and S1. The first index of the hatching rate $\mathrm{SH}$ increased with respect to present conditions for clones that showed the highest extinction rate: $\mathrm{I} 2, \mathrm{~S} 1$ and $\mathrm{I} 1(\mathrm{SH}=0.16, \mathrm{SH}=0.20$ and $\mathrm{SH}=0.27$, respectively). Under present climatic conditions, the deterioration rate (D), the probability that the water balance is positive $(\mathrm{P})$ and the hatching rate $(\mathrm{H})$, were the factors with the highest interaction terms measured for all clones according to the total effect index (Figure 5 and Figure S2 in Supplementary Materials). For all clones, the mean number of resting eggs produced per female (Y) was the factor that showed the lowest value of total index. Among clones, the highest values of STY were recorded in clones that showed the highest extinction rate: I2, S1 and I1 (STY $=0.28, \mathrm{STY}=0.22$ and STY $=0.26$, respectively). Under climate change conditions, for all clones, the total effect index of the deterioration rate (D), STD, decreased, with respect to the present climate conditions. The total effect index of the mean number of resting eggs produced per female $(\mathrm{Y}), \mathrm{STY}$, showed a reduction with respect to the present conditions for all clones with the exception of the northern clone I1 (Figure 5 and Figure S2 in Supplementary Materials). In present conditions, the highest total effect index for the hatching rate $(\mathrm{H}), \mathrm{STH}$, was recorded for clones that showed the highest extinction rate $\mathrm{I} 2, \mathrm{~S} 1$ and $\mathrm{I} 1$ (STH $=0.48, \mathrm{STH}=0.50$ and $\mathrm{STH}=0.53$, respectively). In both climatic conditions, northern clone I1 showed the lowest total effect index for the probability that the water balance is positive $(\mathrm{P})$.

\section{Discussion}

Egg banks play a prominent role for population persistence in short-lived pools characterized by high levels of habitat uncertainty [19]. Egg banks have a key role in aquatic 
crustaceans that cope with environmental uncertainty in temporary ponds and survive recurrent dry periods thanks to drought resistant eggs, from which the following generations are recruited when a suitable hydroperiod is re-established [15,61-63]. The difference in resting egg production, hatching time and hatching rate may have consequences on clonal fitness and persistence. Previous studies have shown that temporary pool zooplankton will face decreasing hydroperiods under climate change $[35,64,65]$. Simulations by Pinceel et al. [37] confirmed that climate change could threaten population persistence despite the presence of an egg bank. In our simulation of egg bank dynamics under climate change conditions, all clones showed a reduction of their extinction rate. This result might be explained considering that, in our simulation, the wet season was indeed shortened but hydroperiod unpredictability was also found to be reduced. Under climate change conditions, the probability of a positive water balance increased in the winter months (November-March) and decreased from April to October, leading to a shorter but more predictable hydroperiod. As a consequence, the risk of egg bank depletion was reduced.

In general, the most important factors involved in viability or extinction varied according to conditions and clones. By global sensitivity (GSA) and uncertainty analysis, and in agreement with our previous results [46], hatching rate $(\mathrm{H})$, egg deterioration rate (D) and the probability that the water balance is positive $(\mathrm{P})$ were the most important factors in determining the extinction of $H$. incongruens' egg banks. By regionalized sensitivity analysis (RSA), we showed that, for all clones, under both present and climate change conditions, the hatching rate $(\mathrm{H})$ and the deterioration rate $(\mathrm{D})$ were negatively correlated: extinction was observed when the fraction of eggs that hatched was low and the deterioration was high. The probability that the water balance is positive $(\mathrm{P})$ and the deterioration rate (D) were positively correlated: extinction events were recorded in co-occurrence with a wet season and a high deterioration rate. The probability that the water balance is positive $(\mathrm{P})$ and the hatching rate $(\mathrm{H})$ were positively correlated for most clones in both conditions. Therefore, extinction rates might be high when $\mathrm{P}$ and $\mathrm{H}$ are high but are not counterbalanced by the high production of resting eggs (Y). According to the factor fixing Morris methods, the initial number of eggs $\left(\mathrm{Eb}_{0}\right)$ was not important for persistence in time but may be in the early stages of the colonization to cope with the random fluctuations of the population and the environment. We assume that this effect loses importance over time, to a negligible effect at the end of the simulation.

According to our results, the extinction rate varied among clonal lineages. The northern winter clones W1 and W2 showed the lowest extinction rates, both in present and in climate change conditions. With respect to the present conditions, this result is supported by field observation, as those clones are the most widespread in northern temporary water bodies and ricefields [39]. For W clonal lineages, the extinction rate was high when $\mathrm{H}$ and $P$ were positively correlated. In present conditions, according to the total Sobol's index, these factors also showed higher interaction terms to determine the egg bank extinction. Short-lived pools typically have a driving selection for lower hatching fractions as part of a bet-hedging strategy and an increase in the importance of the survival of the egg bank $[29,66]$. We found that for all clones, a high deterioration rate with a low hatching rate increased the extinction rate. In winter, when a positive water balance probability is high and unpredictability is low, the emergent effect of a high hatching rate and a consistent production of resting eggs $(\mathrm{Y})$ could counteract the deterioration rate, leading to a global reduction of the extinction rate for typical winter clones $\mathrm{W} 1$ and $\mathrm{W} 2$.

For clones that showed the highest extinction rates, S1, I2 and I1, the interaction term between hatching rate $(\mathrm{H})$ and deterioration rate $(\mathrm{D})$ was higher than in the winter clones (W1 and W2). Sobol's analysis highlights the importance of the mean number of resting eggs produced per female (Y) in reducing the extinction rate. In S1, I2 and I1 clones the mean numbers of resting eggs produced per female $(Y)$ were lower than in W1, W2 and S2 clones [41]. W1, W2 and S2 clones produced a number of resting eggs that better buffer the depletion of the egg bank, cope with environmental fluctuation and prevent local extinctions $[19,67,68]$. Our results suggest a local adaptation of clones W1 and W2 in the Po 
plain [41]. In both climatic conditions, from Sobol's analysis, the mean number of resting eggs produced per female (Y) was an important factor for clones S1, I2 and I1. The highest extinction rates were shown by the I1 and I2 rare clones which, according to our laboratory experiments, did not produce a significant number of resting eggs and by a typical summer clone (S1). S1 is well adapted to artificial ricefield conditions and was considered a "foreign guest", i.e., an allochthonous clonal lineage introduced into Italy by resting eggs along with rice $[56,69]$. Clones I1 and I2 did not have an efficient egg bank and summer clone S1 could not perform well in winter temporary ponds, even in climate change conditions. With an extinction rate higher than 50\%, I1, I2, and S1 clones are critically endangered (according to the IUCN Red List criterion [70]).

Our previous field and laboratory work demonstrated that $H$. incongruens is made up of clones that, for their ecological needs, can be classified as Winter-Spring and Summer clones $[40,41,43]$. In temperate regions, temperature and photoperiod are critical seasonal cues that regulate phenology of plants and animals (e.g., flowering time and dormancy). Temperature is affected by climate change while photoperiod is not [71-75]. The asynchronous change of temperature and photoperiod cues has disrupted the optimal seasonal timing and phenology in many species $[71,76,77]$. Increased temperatures and shorter photoperiods have been reported to decrease Daphnia emergence from resting eggs [78]. In our simulation, the sharper differences between "very wet" and "very dry" seasons might have affected the clones' ability to perceive appropriate seasonal clues. The altered relationship between photoperiod and seasonal hydroperiod creates a mismatch that might affect both the periodic production of resting eggs and the hatching phenology of H. incongruens. In turn, this less accurate detection will produce inappropriate plastic responses in animals that use photoperiod as a predictor of seasonality. A change in climate and hydroperiod may positively affect seasonal timing (phenology) of W1 and W2 clones, as reported in poikilothermic organisms whose development depends on temperature $[79,80]$. Even less understood is the effect of a mismatch between photoperiod and hydroperiod, and the potential for disruption of the phenology of clones $S$ whose deposition and hatching of resting eggs seem driven by other environmental cues such as photoperiod and water chemistry [79]. For instance, at $24^{\circ} \mathrm{C}$, clone $\mathrm{W} 2$ produced more resting eggs at 12:12 L:D than at 16:8 L:D, while clone S1 produced fewer resting eggs at 12:12 L:D than at 16:8 L:D [43].

Under the new climate conditions, due to an increase in the average winter temperature and to a reduction of unpredictability in the hydroperiod regime, seasonal availability of northern ponds could be similar to the one in present conditions in Lampedusa Island, Southern Italy, where, at present, a positive water balance was observed from October to March [33]. In this new simulated scenario, the potential migration northward and the colonization of northern ponds by clonal lineages from the South, could be successful. According to our simulation, the winter clones from southern Italy, clones $\mathrm{L}$, showed an intermediate extinction rate compared to winter and summer northern clones, and, only in clones $\mathrm{L}$, the probability that the water balance is positive $(\mathrm{P})$ and the hatching rate $(\mathrm{H})$ were correlated. The southern clones $\mathrm{L}$ showed a remarkable reduction of the extinction rate in climate change conditions and an increase in the importance of $\mathrm{P}$ was recorded. $\mathrm{P}$ becomes critical in climate change conditions for clones $\mathrm{L}$. According to global sensitivity analysis (GSA), in climate change conditions, the importance of single factors and the reduction of interaction among factors was observed.

Several important factors such as competitive interactions among and between individuals of different clones, predation or any climate-associated environmental changes, were not taken into account in our analysis. However, our different clones represent different ecotypes with different thermal niches and show seasonal succession [33,41]. Persistence and reproduction in ephemeral ponds are independent of population density and depend on the timing of the hydroperiod and the organisms' life cycle [39]. A winter temperature increase may reduce both the developmental time of crustaceans and hydroperiod, due to evaporation $[35,81]$. In this scenario, if the hydroperiod shortens much more 
than the life cycle, the result will be a demographic decline with a depletion of the egg bank proportional to the hatching rate of the resting eggs. Moreover, under climate change conditions, variations in rainfall patterns, temperature and evaporation increase, are expected to increase conductivity levels $[36,64,82]$. In Heterocypris, high conductivity delayed hatching of resting eggs from an egg bank [83]. In contrast to an increase of temperature, increasing of conductivity levels may reduce the hatching rate and the depletion of the egg bank or may reduce growth rates and fecundity of freshwater invertebrates [36]. Coping with hydroperiod uncertainty, organisms "hedge their bets" and adopt an adaptive risk spread strategy, including hatching delays and asynchrony [22-24]. A higher conductivity and a shorter hydroperiod potentially exert a selective pressure that may affect local extinction [84-86]. In the present study, the measure of habitat predictability is based primarily on the probability that a positive water balance is maintained in a pond for a sufficiently long time to allow H. incongruens to complete its life cycle. Perhaps that the probability of a positive water balance is not very meaningful as a proxy for habitat uncertainty and is a simplification in a bet-hedging perspective, where hatching is partly regulated by the environment cues (water, conductivity, temperature, photoperiod, oxygen, etc.) that signal 'good' conditions [87]. However, the probability of a positive water balance is the "condicio sine qua non" for a hydroperiod slot.

Moreover, here, metapopulation dynamics were not taken into account but, in a previous study, a simulation was performed by combining the local dynamics of Heterocypris' egg bank with a metapopulation approach [46]. The persistence of H. incongruens is linked to the egg bank growth rate and to high dispersal by wind, and the extinction rate is negatively correlated with the percentage of colonized ponds. Last but not least, the probability of the population's extinction (under reduced median hydroperiods) could be compensated by changes in life history traits due to phenotypic plasticity or (epi)genetic changes $[6-8,34,37]$. Actually, the potential phenotypic plasticity of many clones and the maternal epigenetic effect on the hatching phenology of $H$. incongruens was shown $[33,40,41,43,45]$.

\section{Conclusions}

In our simulation, in climate change conditions, extinction rates should decline for all different clonal lineages and the extinction risk may vary widely depending on both genetic and ecological diversity. It is hypothesized that $\mathrm{W}$ winter clonal lineages should undergo niche expansion, realizing niche changes to accommodate new climate conditions. The summer clone S2 could undergo a niche shift, but a mismatch between photoperiod and hydroperiod might have a detrimental effect on its fecundity and phenology and accelerate its extinction. Southern winter clonal lineages $\mathrm{L}$, showing intermediate extinction rates, should successfully colonize northern temporary ponds, by passive migration as resting eggs. H. incongruens might respond to climate change in different ways through genetic diversity and phenotypic plasticity, but genetic variability and potential for further adaptive capacity could decline due to global change.

Supplementary Materials: The following are available online at https: / www.mdpi.com/article/ $10.3390 / w 13131828 /$ s1, Table S1. The life table reported the production of resting eggs obtained by two microcosmos experiments $[33,41]$ for each $H$. incongruens clonal lineages and the number of females $(\mathrm{N})$ that produced resting eggs during the experiments. The microcosmos experiments were carried out under three different environmental conditions: Winter $\left(12{ }^{\circ} \mathrm{C}\right.$ and 8 light hours $/ 16$ dark hours), Spring/Autumn $\left(24^{\circ} \mathrm{C}\right.$ and 12 light hours $/ 12$ dark) and Summer $\left(28^{\circ} \mathrm{C}\right.$ and 16 light hours / 8 dark hours). Figure S1. Morris screening on exponential growth model: $\mathrm{Eb}_{0}$ is the number of resting eggs at time $0, \mathrm{H}$ is the hatching rate, $\mathrm{Y}$ is the mean number of resting eggs produced per female, $\mathrm{P}$ is the probability that the water balance is positive and $\mathrm{D}$ is the deterioration rate. The $x$-axis represents the mean absolute value for elementary effect $(\mu)$, a measure of the importance on dispersion in model output, and the y-axis represents the standard deviation of the elementary effects $(\sigma)$, a measure of the degree of the interaction effects between factors. Table S2. For each factor of Cohen equation (Equation (1)) and clonal lineages, distribution and relative parameters were reported for two different climatic conditions: present and climate change. Factors $\mathrm{H}$, 
$\mathrm{D}$ were assumed to be random factors that vary between 0 and 1 in each climatic condition. $\mathrm{P}$ and $\mathrm{Y}$ distributions were estimated by data $[33,43]$. R script S1. LHS sampling method and extinction rate estimation. We sample 1000 combinations of factors and we run the simulation for 30 time steps. Table S3. Correlation coefficients and p values estimated from the correlation analysis. The factor's values were relative to the model output extinction of the egg bank. Figure S2. Hierarchical doughnut chart reported from the center to the border: the two climatic conditions: present and climate change; the factors: hatching rate $(\mathrm{H})$, probability that the water balance is positive $(\mathrm{P})$, the mean number of resting eggs produced per female (Y), and the deterioration rate (D); the clonal lineages: W1, W2, S2, L, I2, S1, and I1; the Sobol first index; and the Sobol total index. Sobol's indices that differ in importance among clones were reported in the manuscript and they were represented underlined and in bold.

Author Contributions: Conceptualization, N.B. and V.R.; methodology, N.B; software and data analysis N.B and R.S.; writing-original draft preparation, N.B.; R.S. and V.R. All authors have read and agreed to the published version of the manuscript.

Funding: This research received no external funding.

Institutional Review Board Statement: Not applicable.

Informed Consent Statement: Not applicable.

Data Availability Statement: Data is contained within the article or Supplementary Materials.

Acknowledgments: We would like to dedicate this paper to the retired Paolo Menozzi. We would thank W. Wilde Menozzi for the English revision and three anonymous reviewers for suggestions. This study was supported by FIL, University of Parma. NB was supported by the PhD program in Evolutionary Biology and Ecology (University of Parma, agreement with University of Ferrara and University of Firenze). This work has been carried out in the frame of the activities of the 'COMP-HUB' Initiative, funded by the 'Departments of Excellence' Project of the Italian Ministry for Education, University and Research (MIUR).

Conflicts of Interest: The authors declare no conflict of interest.

\section{References}

1. Urban, M.C. Accelerating extinction risk from climate change. Science 2015, 348, 571-573. [CrossRef] [PubMed]

2. Vadadi-Fülöp, C.; Sipkay, C.; Mészáros, G.; Hufnagel, L. Climate change and freshwater zooplankton: What does it boil down to? Aquat. Ecol. 2012, 46, 501-519. [CrossRef]

3. Wiens, J.J. Climate-Related Local Extinctions Are Already Widespread among Plant and Animal Species. PLoS Biol. 2016, 14, 1-18. [CrossRef] [PubMed]

4. Catullo, R.A.; Llewelyn, J.; Phillips, B.L.; Moritz, C.C. The Potential for Rapid Evolution under Anthropogenic Climate Change. Curr. Biol. 2019, 29, R996-R1007. [CrossRef]

5. Diniz-Filho, J.A.F.; Bini, L.M. Will life find a way out? Evolutionary rescue and Darwinian adaptation to climate change. Perspect. Ecol. Conserv. 2019, 17, 117-121. [CrossRef]

6. Gienapp, P.; Teplitsky, C.; Alho, J.S.; Mills, J.A.; Merilä, J. Climate change and evolution: Disentangling environmental and genetic responses. Mol. Ecol. 2008, 17, 167-178. [CrossRef]

7. Hoffmann, A.A.; Sgró, C.M. Climate change and evolutionary adaptation. Nature 2011, 470, 479-485. [CrossRef]

8. Moritz, C.; Agudo, R. The future of species under climate change: Resilience or decline? Science 2013, 341, 504-508. [CrossRef]

9. Román-Palacios, C.; Wiens, J.J. Recent responses to climate change reveal the drivers of species extinction and survival. Proc. Natl. Acad. Sci. USA 2020, 117, 4211-4217. [CrossRef] [PubMed]

10. Waldvogel, A.; Feldmeyer, B.; Rolshausen, G.; Exposito-Alonso, M.; Rellstab, C.; Kofler, R.; Mock, T.; Schmid, K.; Schmitt, I.; Bataillon, T.; et al. Evolutionary genomics can improve prediction of species' responses to climate change. Evol. Lett. 2020, 4, 4-18. [CrossRef]

11. Williams, S.E.; Shoo, L.P.; Isaac, J.L.; Hoffmann, A.A.; Langham, G. Towards an integrated framework for assessing the vulnerability of species to climate change. PLoS Biol. 2008, 6. [CrossRef] [PubMed]

12. Carvalho, S.B.; Torres, J.; Tarroso, P.; Velo-Antón, G. Genes on the edge: A framework to detect genetic diversity imperiled by climate change. Glob. Chang. Biol. 2019, 25, 4034-4047. [CrossRef]

13. Razgour, O.; Forester, B.; Taggart, J.B.; Bekaert, M.; Juste, J.; Ibáñez, C.; Puechmaille, S.J.; Novella-Fernandez, R.; Alberdi, A.; Manel, S. Considering adaptive genetic variation in climate change vulnerability assessment reduces species range loss projections. Proc. Natl. Acad. Sci. USA 2019, 116, 10418-10423. [CrossRef]

14. Matesanz, S.; Ramírez-Valiente, J.A. A review and meta-analysis of intraspecific differences in phenotypic plasticity: Implications to forecast plant responses to climate change. Glob. Ecol. Biogeogr. 2019, 28, 1682-1694. [CrossRef] 
15. Brendonck, L.; Pinceel, T.; Ortells, R. Dormancy and dispersal as mediators of zooplankton population and community dynamics along a hydrological disturbance gradient in inland temporary pools. Hydrobiologia 2017, 796, 201-222. [CrossRef]

16. Brock, M.A.; Nielsen, D.L.; Shiel, R.J.; Green, J.D.; Langley, J.D. Drought and aquatic community resilience: The role of eggs and seeds in sediments of temporary wetlands. Freshw. Biol. 2003, 48, 1207-1218. [CrossRef]

17. Cáceres, C.E. Seasonal dynamics and interspecific competition in Oneida Lake Daphnia. Oecologia 1998, 115, 233-244. [CrossRef] [PubMed]

18. De Meester, L.; Declerck, S.; Stoks, R.; Louette, G.; Van De Meutter, F.; De Bie, T.; Michels, E.; Brendonck, L. Ponds and pools as model systems in conservation biology, ecology and evolutionary biology. Aquat. Conserv. Mar. Freshw. Ecosyst. 2005, 15, 715-725. [CrossRef]

19. Brendonck, L.; De Meester, L. Egg banks in freshwater zooplankton: Evolutionary and ecological archives in the sediment. Hydrobiologia 2003, 491, 65-84. [CrossRef]

20. De Stasio, B.T. The seed bank of a freshwater crustacean: Copepodology for the plant ecologist. Ecology 1989, 70, 1377-1389. [CrossRef]

21. Hairston, N.G.; De Stasio, B.T. Rate of evolution slowed by a dormant propagule pool. Nature 1988, 336, 239-242. [CrossRef]

22. Cohen, D. Optimizing reproduction in a randomly varying environment. J. Theor. Biol. 1966, 12, 119-129. [CrossRef]

23. García-Roger, E.M.; Serra, M.; Carmona, M.J. Bet-hedging in diapausing egg hatching of temporary rotifer populations-A review of models and new insights. Int. Rev. Hydrobiol. 2014, 99, 96-106. [CrossRef]

24. Maffei, C.; Vagaggini, D.; Zarattini, P.; Mura, G. The dormancy problem for Crustacea Anostraca: A rigorous model connecting hatching strategies and environmental conditions. Ecol. Modell. 2005, 185, 469-481. [CrossRef]

25. Spencer, M.; Colegrave, N.; Schwartz, S.S. Hatching fraction and timing of resting stage production in seasonal environments: Effects of density dependence and uncertain season length. J. Evol. Biol. 2001, 14, 357-367. [CrossRef]

26. Gianuca, A.T.; Declerck, S.A.J.; Lemmens, P.; De Meester, L. Effects of dispersal and environmental heterogeneity on the replacement and nestedness components of $\beta$-diversity. Ecology 2017, 98, 525-533. [CrossRef]

27. Childs, D.Z.; Metcalf, C.J.E.; Rees, M. Evolutionary bet-hedging in the real world: Empirical evidence and challenges revealed by plants. Proc. R. Soc. B Biol. Sci. 2010, 277, 3055-3064. [CrossRef]

28. Gremer, J.R.; Venable, D.L. Bet hedging in desert winter annual plants: Optimal germination strategies in a variable environment. Ecol. Lett. 2014, 17, 380-387. [CrossRef]

29. Simons, A.M. Modes of response to environmental change and the elusive empirical evidence for bet hedging. Proc. R. Soc. B Biol. Sci. 2011, 278, 1601-1609. [CrossRef]

30. Pinceel, T.; Vanschoenwinkel, B.; Hawinkel, W.; Tuytens, K.; Brendonck, L. Aridity promotes bet hedging via delayed hatching: A case study with two temporary pond crustaceans along a latitudinal gradient. Oecologia 2017, 184, 161-170. [CrossRef]

31. Saiah, H.; Perrin, N. Autumnal vs Spring Hatching in the Fairy Shrimp Siphonophanes grubii (Dybowski) (Crustacea, Anostraca): Diversified Bet-Hedging Strategy? Funct. Ecol. 1990, 4, 769. [CrossRef]

32. Ripley, B.J.; Holtz, J.; Simovich, M.A. Cyst bank life-history model for a fairy shrimp from ephemeral ponds. Freshw. Biol. 2004, 49, 221-231. [CrossRef]

33. Rossi, V.; Gandolfi, A.; Menozzi, P. Mother's Age and Hatching Phenology Strategy of Heterocypris incongruens (Crustacea: Ostracoda) in Unpredictable Environment. J. Exp. Zool. Part A Ecol. Genet. Physiol. 2016, 325, 701-712. [CrossRef] [PubMed]

34. Pearson, R.G.; Stanton, J.C.; Shoemaker, K.T.; Aiello-Lammens, M.E.; Ersts, P.J.; Horning, N.; Fordham, D.A.; Raxworthy, C.J.; Ryu, H.Y.; Mcnees, J.; et al. Life history and spatial traits predict extinction risk due to climate change. Nat. Clim. Chang. 2014, 4, 217-221. [CrossRef]

35. Pyke, C.R. Assessing climate change impacts on vernal pool ecosystems and endemic branchiopods. Ecosystems 2005, 8, 95-105. [CrossRef]

36. Stoks, R.; Geerts, A.N.; De Meester, L. Evolutionary and plastic responses of freshwater invertebrates to climate change: Realized patterns and future potential. Evol. Appl. 2014, 7, 42-55. [CrossRef]

37. Pinceel, T.; Vanschoenwinkel, B.; Brendonck, L.; Buschke, F. Modelling the sensitivity of life history traits to climate change in a temporary pool crustacean. Sci. Rep. 2016, 6, 1-5. [CrossRef]

38. Meisch, C. Freshwater Ostracoda of Western and Central Europe; Spektrum Akademischer Verlag: Heidelberg, Germany, 2000.

39. Rossi, V.; Benassi, G.; Belletti, F.; Menozzi, P. Colonization, population dynamics, predatory behaviour and cannibalism in Heterocypris incongruens (Crustacea: Ostracoda). J. Limnol. 2011, 70, 102-108. [CrossRef]

40. Rossi, V.; Menozzi, P. The Clonal Ecology of Heterocypris incongruens (Ostracoda). Oikos 1990, 57, 388. [CrossRef]

41. Rossi, V.; Gandolfi, A.; Menozzi, P. Egg diapause and clonal structure in parthenogenetic populations of Heterocypris incongruens (Ostracoda). Hydrobiologia 1996, 320, 45-54. [CrossRef]

42. Rossi, V.; Gandolfi, A.; Baraldi, F.; Bellavere, C.; Menozzi, P. Phylogenetic relationships of coexisting Heterocypris (Crustacea, Ostracoda) lineages with different reproductive modes from Lampedusa Island (Italy). Mol. Phylogenet. Evol. 2007, 44, 1273-1283. [CrossRef] [PubMed]

43. Rossi, V.; Menozzi, P. The Clonal Ecology of Heterocypris incongruens (Ostracoda): Life-History Traits and Photoperiod. Funct. Ecol. 1993, 7, 177. [CrossRef]

44. Rossi, V.; Martorella, A.; Menozzi, P. Hatching phenology and voltinism of Heterocypris barbara (Crustacea: Ostracoda) from Lampedusa (Sicily, Italy). J. Limnol. 2013, 72, 227-237. [CrossRef] 
45. Rossi, V.; Albini, D.; Benassi, G.; Menozzi, P. To rest in hydration: Hatching phenology of resting eggs of Heterocypris incongruens (crustacea: Ostracoda). Fundam. Appl. Limnol. 2012, 181, 49-58. [CrossRef]

46. Bellin, N.; Groppi, M.; Rossi, V. A model of egg bank dynamics in ephemeral ponds. Ecol. Modell. 2020, 430, 109126. [CrossRef]

47. Saltelli, A.; Ratto, M.; Andres, T.; Campolongo, F.; Cariboni, J.; Gatelli, D.; Saisana, M.; Tarantola, S. Global Sensitivity Analysis: The Primer; John Wiley and Sons, Inc.: Hoboken, NJ, USA, 2008.

48. Marino, S.; Hogue, I.B.; Ray, C.J.; Kirschner, D.E. A methodology for performing global uncertainty and sensitivity analysis in systems biology. J. Theor. Biol. 2008, 254, 178-196. [CrossRef]

49. Convertino, M.; Muñoz-Carpena, R.; Chu-Agor, M.L.; Kiker, G.A.; Linkov, I. Untangling drivers of species distributions: Global sensitivity and uncertainty analyses of MaxEnt. Environ. Model. Softw. 2014, 51, 296-309. [CrossRef]

50. Pianosi, F.; Beven, K.; Freer, J.; Hall, J.W.; Rougier, J.; Stephenson, D.B.; Wagener, T. Sensitivity analysis of environmental models: A systematic review with practical workflow. Environ. Model. Softw. 2016, 79, 214-232. [CrossRef]

51. Dazzi, C.; Costantini, E. (Eds.) The Soils of Italy, 1st ed.; Springer: Dordrecht, The Netherlands, 2013.

52. Celico, P. Prospezioni Idrogeologiche Vol. I e II.; Liguori Editore: Napoli, Italy, 1988.

53. Rossi, M.; Donnini, M. Estimation of regional scale effective infiltration using an open source hydrogeological balance model and free/open data. Environ. Model. Softw. 2018, 104, 153-170. [CrossRef]

54. Trouet, V.; Van Oldenborgh, G.J. KNMI climate explorer: A web-based research tool for high-resolution paleoclimatology. Tree-Ring Res. 2013, 69, 3-13. [CrossRef]

55. Fifth assessment report of the intergovernmental panel on climate change. In IPCC Climate Change 2014: Synthesis Report; IPCC: Geneva, Switzerland, 2014.

56. Rossi, V.; Benassi, G.; Veneri, M.; Bellavere, C.; Menozzi, P.; Moroni, A.; Mckenzie, K.G. Ostracoda of the Italian ricefields thirty years on: New synthesis and hypothesis. J. Limnol. 2003, 62, 1. [CrossRef]

57. Team, R.C. R: A Language and Environment for Statistical Computing; R Foundation for Statistical Computing: Vienna, Austria, 2017.

58. Helton, J.C.; Davis, F.J. Latin hypercube sampling and the propagation of uncertainty in analyses of complex systems. Reliab. Eng. Syst. Saf. 2003, 81, 23-69. [CrossRef]

59. Saltelli, A.; Tarantola, S.; Campolongo, F.; Ratto, M. Sensitivity Analysis in Practice: A Guide to Assessing Scientific Models; Wiley: Hoboken, NJ, USA, 2004; ISBN 0470870931.

60. Saltelli, A.; Annoni, P.; Azzini, I.; Campolongo, F.; Ratto, M.; Tarantola, S. Variance based sensitivity analysis of model output. Design and estimator for the total sensitivity index. Comput. Phys. Commun. 2010, 181, 259-270. [CrossRef]

61. King, J.L.; Simovich, M.A.; Brusca, R.C. Species richness, endemism and ecology of crustacean assemblages in Northern California vernal pools. Hydrobiologia 1996, 328, 85-116. [CrossRef]

62. Wiggins, G.B.; Rosemary, J.M.; Smith, I.M. Evolutionary and Ecological Strategies of Animals in Annual Temporary Pools; Archiv für Hydrobiologie; Schweizerbart: Stuttgart, Germany, 1980.

63. Williams, D.D. The Biology of Temporary Waters; Oxford University Press: Oxford, UK, 2006.

64. Moss, B. Climate change, nutrient pollution and the bargain of Dr Faustus. Freshw. Biol. 2010, 55, 175-187. [CrossRef]

65. Tuytens, K.; Vanschoenwinkel, B.; Waterkeyn, A.; Brendonck, L. Predictions of climate change infer increased environmental harshness and altered connectivity in a cluster of temporary pools. Freshw. Biol. 2014, 59, 955-968. [CrossRef]

66. Evans, M.E.K.; Dennehy, J.J. Germ banking: Bet-hedging and variable release from egg and seed dormancy. Q. Rev. Biol. 2005, 80, 431-451. [CrossRef] [PubMed]

67. Gyllström, M.; Hansson, L.A. Dormancy in freshwater zooplankton: Induction, termination and the importance of benthic-pelagic coupling. Aquat. Sci. 2004, 66, 274-295. [CrossRef]

68. Nunney, L. The effective size of annual plant populations: The interaction of a seed bank with fluctuating population size in maintaining genetic variation. Am. Nat. 2002, 160, 195-204. [CrossRef]

69. Rossi, V.; Benassi, G.; Leonardi, S.; Piotti, A.; Menozzi, P. Clonal diversity of Heterocypris incongruens (Crustacea: Ostracoda) in Northern Italian ricefields. Arch. Hydrobiol. 2006, 166, 225-240. [CrossRef]

70. Kindvall, O.; Gärdenfors, U. Temporal extrapolation of PVA results in relation to the IUCN red list criterion E. Conserv. Biol. 2003, 17, 316-321. [CrossRef]

71. Bradshaw, W.E.; Holzapfel, C.M. Evolution of animal photoperiodism. Annu. Rev. Ecol. Evol. Syst. 2007, 38, 1-25. [CrossRef]

72. Dawson, A.; King, V.M.; Bentley, G.E.; Ball, G.F. Photoperiodic control of seasonality in birds. J. Biol. Rhythms 2001, 16, 365-380. [CrossRef] [PubMed]

73. Nielsen, M.E.; Kingsolver, J.G. Compensating for climate change-Induced cue-environment mismatches: Evidence for contemporary evolution of a photoperiodic reaction norm in Colias butterflies. Ecol. Lett. 2020, 23, 1129-1136. [CrossRef]

74. Nylin, S. Induction of diapause and seasonal morphs in butterflies and other insects: Knowns, unknowns and the challenge of integration. Physiol. Entomol. 2013, 38, 96-104. [CrossRef]

75. Walton, J.C.; Weil, Z.M.; Nelson, R.J. Influence of photoperiod on hormones, behavior, and immune function. Front. Neuroendocrinol. 2011, 32, 303-319. [CrossRef]

76. Bradshaw, W.E.; Holzapfel, C.M. Light, time, and the physiology of biotic response to rapid climate change in animals. Annu. Rev. Physiol. 2009, 72, 147-166. [CrossRef] [PubMed]

77. Grevstad, F.S.; Coop, L.B. The consequences of photoperiodism for organisms in new climates. Ecol. Appl. 2015, 25, 1506-1517. [CrossRef] 
78. Dupuis, A.P.; Hann, B.J. Climate change, diapause termination and zooplankton population dynamics: An experimental and modelling approach. Freshw. Biol. 2009, 54, 221-235. [CrossRef]

79. Rossi, V.; Rozzi, M.C.; Menozzi, P. Life strategy differences among electrophoretic clones of Heterocypris incongruens (Crustacea, Ostracoda). Verandlungen des Int. Verain Limnol. 1991, 24, 2816-2819. [CrossRef]

80. Gillooly, J.F.; Charnov, E.L.; West, G.B.; Savage, V.M.; Brown, J.H. Effects of size and temperature on developmental time. Nature 2002, 417, 70-73. [CrossRef] [PubMed]

81. Vanschoenwinkel, B.; Brendonck, L.; Pinceel, T.; Dupriez, P.; Waterkeyn, A. Rediscovery of Branchipus schaefferi (Branchiopoda: Anostraca) in Belgium-Notes on habitat requirements and conservation management. Belgian J. Zool. 2013, 143, 3-14.

82. Schindler, D.W. The cumulative effects of climate warming and other human stresses on Canadian freshwaters in the new millennium. Can. J. Fish. Aquat. Sci. 2001, 58, 18-29. [CrossRef]

83. Rossi, V.; Martorella, A.; Scudieri, D.; Menozzi, P. Seasonal niche partitioning and coexistence of amphimictic and parthenogenetic lineages of Heterocypris barbara (Crustacea: Ostracoda). Can. J. Zool. 2017, 95, 7-14. [CrossRef]

84. Halse, S.A.; Ruprecht, J.K.; Pinder, A.M. Salinisation and prospects for biodiversity in rivers and wetlands of south-west Western Australia. Aust. J. Bot. 2003, 51, 673-688. [CrossRef]

85. Loureiro, C.; Pereira, J.L.; Pedrosa, M.A.; Gonçalves, F.; Castro, B.B. Competitive Outcome of Daphnia-Simocephalus Experimental Microcosms: Salinity versus Priority Effects. PLoS ONE 2013, 8, e70572. [CrossRef] [PubMed]

86. Wellborn, G.A.; Skelly, D.K.; Werner, E.E. Mechanisms creating community structure across a freshwater habitat gradient. Annu. Rev. Ecol. Syst. 1996, 27, 337-363. [CrossRef]

87. Simons, A.M. Playing smart vs. playing safe: The joint expression of phenotypic plasticity and potential bet hedging across and within thermal environments. J. Evol. Biol. 2014, 27, 1047-1056. [CrossRef] [PubMed] 